\title{
On truth-telling and storytelling: Truth-seeking during research involving communities with an oral culture and a history of violent conflict
}

\author{
$A G$ VELTHUIZEN ${ }^{1}$
}

\begin{abstract}
The aim of this article is to propose some principles and practices for truth-seeking during research into violent conflict. To achieve this aim, an argument is deployed by analysing the theoretical concepts "truth", "myth" and "oral culture" as sources of knowledge. This conceptual analysis precedes a discussion on community-based participatory research (CBPR) as a research methodology to access the knowledge of lived experiences embedded in the oral culture of the San community of Platfontein, near Kimberley, South Africa. It was found that CBPR contains good practices to use in research to judge the probable truth about disputes. The CBPR process is ideal for determining the accuracy of data in the context of a specific culture, considering the norms, spiritual influences and personal considerations of knowledge-holders that accompany a unique cosmology. A variety and equity of worldviews and perspectives of what happened during violent conflict successfully challenges hegemonic power relationships, paradigms and narratives, ultimately leading to informed judgements of what is probably true about a conflict. CBPR with the San of Platfontein revealed principles that can be used as guidelines for researching disputes where oral culture is involved.
\end{abstract}

Keywords: truth, myth, oral culture, CBPR, San, conflict, dispute

\section{Introduction}

This article is not about "the truth shall set you free" and other clichés, but more about what Tolstoy affirms: "There is only one thing, and only one thing, in which it is granted to you to be free in life, all else being beyond your power: that is to recognise and profess the truth."

The article is therefore inspired by the quest to find the truth about events of the past that informs the present and opens the mind to new possibilities and a better way of living. We should not hesitate to use "truth" to find and implement solutions leading to a better world. However, finding the truth is the challenge. The question that always remains is whether the truth we perceive is always "true" in all circumstances. Finding the truth is even more of a

Senior Researcher in the Institute for Dispute Resolution in Africa, College of Law,

Tolstoy, L. 2008. The Kingdom of God is within you. Radford: Wilder Publications, p. 240. 
challenge if it is intentionally hidden or forgotten or manipulated. In the case of dramatic events, such as violent conflict, one may instinctively change the facts to make the experience acceptable to the listener which is always a challenge for research into violent conflict. In this regard, the San people of Platfontein have much knowledge, gained over a long period, to share about the avoidance of conflict and dealing with violence. ${ }^{3}$ The journey with the San is part of a never-ending quest for knowledge that can bring about human development and understanding of the world in which we live.

Against this background the research problem arises: How do researchers process narratives from an oral culture such as that of the San to establish the truth about the causes, dynamics and consequences of violent conflict? To solve this problem, the article proposes some principles and practices for truth-seeking during research into violent conflict.

In pursuit of this aim, it is argued that there are many perspectives on what happened during violent conflict. Therefore a methodology is required that merges all valid perspectives into a body of knowledge that can be regarded as sufficiently truthful to be used for policy-making and the implementation of interventions.

This argument is deployed by analysing the concepts "truth", "myth" and "oral culture" as sources of knowledge. The conceptual analysis opens the way for a discussion on communitybased participatory research as a research methodology to access the knowledge of lived experiences embedded in an oral culture, in this case the San community of Platfontein near Kimberley in South Africa.

\section{Conceptual framework}

What is "the truth"?

Although there are many theories of truth, for the purpose of this article they can roughly be divided into correspondence theory, coherence theory and pragmatic theory.

\section{Correspondence theory of truth}

Correspondence theory has its foundation in the work of Greek philosophers, mainly Socrates, Plato and Aristotle. The basic argument is that the truth is an accurate description of things. ${ }^{4}$ Plato claims that human intelligence is capable of reaching the spiritual, moral and educational essence of existence in the context of other elements. ${ }^{5}$ According to Aristotle, underlying things ("pragmata") render statements as fact or situations if they are logically structured. ${ }^{6}$ Thomas Aquinas emphasised conforming to reality as the foundation of truth; he

3 See the San Dispute Resolution Oral Archive http://uir.unisa.ac.za (restricted access) for research reports on the dispute resolution knowledge of the San.

4 Prior, A.N. 1969.'Correspondence theory of truth'. In Encyclopaedia of Philosophy (2). London: Macmillan, pp. 223-224.

Ibid, 223.

David, M. 2005. 'Correspondence theory of truth'. In Stanford Encyclopedia of Philosophy. Available at http://plato.stanford.edu/entries/truth-correspondence/ (accessed 25 September 2014). 
claimed that truth is the application of the intellect to things. Being or reality is the foundation of truth, which is found in the human mind, acquired through human senses, understanding, reason and judgement. ${ }^{7}$

In the context of this paper, these affirmations mean that truth-seeking after violent conflict requires complete accuracy of description in the context in which the conflict takes place. Furthermore, if these suggestions are accepted, the truth is not only empirical, but subject to reflection and taking a certain position on what can be regarded as true.

\section{Coherence theory of truth}

According to coherence theory ${ }^{8}$, truth requires a proper fit of elements into the whole. Coherence implies more than logical consistency: it requires that propositions in a coherent system imply mutual support of each other. The completeness of a set of concepts is critical to validating the usefulness of a whole system. Coherence may entail many true systems or one absolute system. One such coherent system was developed by the rationalist philosophers such as Kant, Spinoza and Leibnitz. Coherence systems are challenged because they cannot be justified by practicality. Heidegger ${ }^{9}$ emphasised conforming to reality. However he was seeking to expand the notion of "correspondence truth", pointing out that it is rooted in a more original or "primordial" truth, called aletheia, which is disclosure, unveiling and uncovering as condition for true correspondence and the ontological condition for assertions to be true or false.

If the above propositions are analysed, they imply that empirical investigation is required at the place where the specific violent event took place. The "truth" can then be claimed when it is disclosed by participants in the event, or deliberately found through methods of investigation. If these discoveries are then placed in the context of a coherent system, they can be validated as truth. If read together with the requirement of correspondence (as suggested by the Greek philosophers), to be valid truth requires not only coherence, but also accuracy and critical reflection of where the facts fit into the whole.

\section{Pragmatic theory of truth}

Pragmatists reject the notion of absolute truth and do not make metaphysical claims about the world, seeking to bridge the gap between correspondence theory and coherence theory. Truth comes from experience and can only be verified by results if put into practice. Charles Pierce $^{10}$, for instance, asserts that truth starts with an abstract concept that is then subjected to endless investigation, leading towards "scientific belief". Confession of inaccuracy or onesidedness is an essential ingredient of finding the truth. According to Dewey, ${ }^{11}$ scientific,

Prior, ibid, 224.

8 White, A.R. 1969. 'Coherence theory of truth'. In Encyclopedia of Philosophy. London: Macmillan, p.130.

$9 \quad$ Heidegger, M. 1972. On time and being. New York: Harper \& Row, p.70.

10 Pierce, C.S. 1901. 'Truth and falsity and error'. In J.M. Baldwin (ed.), Dictionary of Philosophy and Psychology (2, pp. 718-720.

11 Bernstein, R.J. 1969. 'Dewey, John'. In Encyclopedia of Philosophy (2). London: Macmillan, p.383. 
technical, sociological, philosophical and cultural inquiry is self-corrective if openly submitted for testing by a community of inquirers, during which clarification, justification, refinement or refutation take place.

Foucault ${ }^{12}$ is concerned with the way in which power positions affect views of realities. He asserts that power is a relationship between individuals and that relationships play a role in what is believed to be true. Every human relationship is to some degree a power relationship or a perpetual strategic relationship. ${ }^{13}$ Because of this relationship, there are multiple histories of the same events, but from different perspectives within different power relationships. Foucault encourages people to reject dogmatic worldviews, and suggests that various forms of rationality are desirable to unsettle certitudes. ${ }^{14}$ However, a plethora of accounts of the same events poses the challenge of reflecting on everything. ${ }^{15}$

These assertions imply that to discover the truth after violent conflict requires extensive research covering a relatively long time, in order to gather all the perceptions of what happened and to validate data without rejecting any perspectives as "incorrect" because they do not fit into any dominant narrative or belief system. Seeking the truth about violent conflict also requires sufficient time to allow for the discovery of accurate explanations in the space where it happened, to evaluate, analyse and reflect on all the perspectives and to judge where power relationships and continued strategic contests distort perspectives.

\section{Myth}

Myths are popularly defined as tales believed to be true, usually sacred, set in the distant past or other worlds or parts of the world, and with extra-human, non-human or heroic characters. ${ }^{16}$ However, myths can also be functional, as narratives that are formative or reflective of a social order or values within a culture. Paul Radin ${ }^{17}$ describes myth as a distinctive function and implication determined by individual members of society, calling them "the myth-makers", who explain symbolically how people live. The explanatory theme may be so dominant that everything else becomes subordinated to it.

Myths can also be representative of a particular epistemology, coherent in terms of myth and history (structuralist). Claude Levi-Strauss ${ }^{18}$ explains that sometimes anthropologists collect myths in "shreds" and "patches" as disconnected stories without relationships to each other.

Foucault, M. 1998. Politics, philosophy, culture: interviews and other writings 1977-1984. In L.D. Kritzman (ed)., Politics, Philosophy, Culture: Interviews and Other Writings, New York: Routledge, p.83.

Ibid, 168.

Ibid, 883.

Ibid, 327.

Bascom, W. 1965. The forms of folklore: prose narratives. Journal of American Folklore (78), pp. 3-20.

Radin, P. 1950. 'The basic myth of the North American Indians'. In Eranos-Jahrbuch: Der Mensch und die Mythische Welt. Zurich: Rhein-Verlag, pp. 359-419.

Levi-Strauss, C. 1978. Myth and meaning. New York: Routledge, pp. 29-37. 
This disconnected state may be an anarchic one where "native wise men" and "philosophers" put together the myths to be collected by anthropologists from outside the society. The question is: where does mythology end and where does history begin in a society without archives and only a verbal tradition?

Levi-Strauss continues to answer this question, explaining that the basic structures of the story may be the same, but the content may differ. Therefore, one property of a myth is that it can be observed under different transformations, with the transformation of one element requiring other elements to be rearranged. The same mythical elements may be combined repeatedly in a closed system. History, being an open system, allows explanations to be arranged and then rearranged, using the same material, building up an original account. Two different accounts can be accepted as true even when one account is better or more accurate than the other or at least equally valid. To avoid these accounts being imaginary, a better understanding of history can be obtained by salvage archaeology, by establishing correspondence (what corresponds and what does not), bridging the gap in our minds between mythology and history.

Cillian McGrattan explains that social groups construct their own historical narratives, but questions if entire societies can "work through" the past. Many "truths" emerge in postconflict situations, but those "truths" should be tested against evidence by working through other archival evidence and oral history. Historians have to point out the moral and political assumptions as well as compromises that often "lie at the heart" of narratives, to allow for more rational debate over responsibility for actions in the past. Furthermore, creating greater space for marginalised voices, such as those of victims, the elderly, or women, helps to broaden the concept of peace from being merely about expediency to being about justice, discussion and consensus. ${ }^{19}$

An analysis of these propositions about myth sensitises the researcher who investigates the history of violent conflict to the probability that stories created by prominent people may become a dominant narrative and framework for analysis for everything that happened in the past. To overcome this trap it is important for the researcher to find the pattern of relationships between variables in content of as many narratives as possible, including those by voices that have been deliberately marginalised and silenced in the past. The findings of this research should be verified using other ways of investigating historical truths, such as finding physical evidence of what happened (for example artefacts), and acknowledging that all knowledge claims are subject to interpretation.

\section{Oral culture}

According to Ong, ${ }^{20}$ in an oral culture the theory "you know what you can recall" is relevant. How do people in an oral culture recall what happened? An oral culture has no texts. An

19 McGrattan, C. 2011. 'Historians in post-conflict societies: Northern Ireland after the Troubles'. Available at http://www.historyandpolicy.org/policy-papers/papers/historians-inpost-conflict-societies-northern-ireland-after-the-troubles (accessed 23 September 2014).

20

Ong, W.J. 2005. Orality and literacy: the technologizing of the word. Taylor and Francis e-

Library, $\quad$ pp. 36-145. Available at http://occupytampa.org/files/wcom/ong\%20walter\%20orality\%20and\%20literacy.pdf (accessed 23 September 2014). 
interlocutor is essential. Sustained thought in an oral culture is therefore tied to communication. Experience can be put into any words, transforming it a little without falsifying it, to recall the experience. Orality is more elaborate than individual words with a mnemonic base of thought (a pattern of ideas or associations that help one to remember something). Furthermore, orality is additive (the use of "and"); aggregative (oral cultures prefer the "brave soldier" to just "the soldier"); fluent; excessive; voluble; and conservative (repeating what is known). Moreover, orality is close to the "human life world" in the sense that oral cultures must conceptualise and verbalise all their knowledge with reference to familiar interactions of human beings. Orality is also empathetic and participatory, using concepts in realistic frames of reference, identifying with the known. Oral narrative in primary oral cultures is agonistic in tone, using proverbs and riddles to engage in verbal and intellectual contests with passionate descriptions of physical violence, which can be explained in terms of persistent physical hardships and violence in many societies. Oral societies are homeostatic (they tend to maintain internal stability) by living in the present, maintaining stability by getting rid of memories which no longer have present relevance. Oral memorisation is subject to direct social pressures and changes the narrator's judgement of what audiences need or tolerate. For oral cultures, the cosmos is perpetual with man at its centre, with the audience becoming one with the speaker. An oral culture cannot deliver a lengthy, sizeable, climactic linear plot, cannot organise even shorter narrative in an intellectual, relentless climactic way and is not much concerned with exact sequence or extranarrative references. Therefore, the examination of phenomena or truth claims is impossible without writing and reading.

Some people in primary oral cultures may not have been exposed to writing in any form, but can produce powerful and valuable verbal "performance of high artistic and human worth". This may no longer have been possible once writing took over the mind. However, without writing, human consciousness cannot achieve its full potential. Orality is destined to and needs to produce written knowledge. ${ }^{21}$

Vansina ${ }^{22}$ defined oral traditions as documents of the present inheriting a message from the past, encompassing all verbal testimonies concerning the past. Oral materials can be of value to historians, whether in the form of proverbs, poetry, songs or epics. These oral materials should be regarded in the same way as written documents to avoid exploitation by deliberately being fed historical information. Most ethnographers accept oral tradition as sources of history. However, ethnologists who have attempted to study the history of people without writing have faced challenges, causing them to believe that oral traditions are not reliable even if they contain some truth, because it is impossible to assess the amount of truth contained in orality. Oral narratives should be methodically examined for validity and reliability, as is done for written text, to see what distortions are most likely and to assess the value of narratives as historical evidence.

From these statements it can be inferred that narratives from people who belong to an oral culture are essential to uncover the truth about what happened before, during and after violent conflict if the people were participants, victims or observers in a conflict. In an oral culture, important information about how the teller personally experienced the past is

$$
\text { Ibid, pp. 8-14. }
$$

Vansina, J. 1965. Oral tradition: a study in historical methodology. Translated by H.M. Wright. Harmondsworth: Penguin, synopsis. 
conveyed to the researcher as interlocutor. It is for the researcher as receiver of these messages to determine the pattern of associations that is made during the narrative, accepting that there may be much "noise" because of the sometimes-colourful use of language or the narrator subscribing to a popular dominant narrative or myth. It is for the researcher to acknowledge the limitations that come with the use of language: sometimes peers want the story to be told in a certain way, or important facts are omitted because the storyteller considers them irrelevant, shameful or hurtful. Furthermore, it is important for the researcher to interpret the message in terms of the cosmology of the specific culture: many oral cultures sees personhood and the universe as one, expecting the listener to understand where the narrative fits in a broader scheme (for instance spirituality), without necessarily referring to it specifically. It is therefore important that as many narratives as possible are captured, so that they can be subjected to validation, evaluation, analysis and interpretation to allow for judging what the truth about what happened is - in other words a thorough research process.

\section{Seeking the truth in the narratives of post-conflict society}

Braithwaite $^{23}$ found that there are many sequences of truth, justice and reconciliation. One sequence takes place in a "top-down truth zone" where reconciliation can take place on a foundation of only partial truths, where partial truth and reconciliation are mutually supportive. An alternative sequence takes place in the "expanding zone" that enables high integrity top-down truth-telling to call on bottom-up truth telling for reconciliation. A third sequence takes place in a "networked zone", where peace-builders network across organisations to respond to local voices and build on the virtues of a network towards reconciliation.

Lundy and $\mathrm{McGovern}{ }^{24}$ remind us that only people who are inside a community can gain access to key individuals, groups and sensitive information that is often off-limits to "outside" researchers. Because they are trusted, "insiders" may be able to penetrate some of the most unconquerable silences. When researching violently divided societies, providing an opportunity for excluded and alienated voices to be heard is important for post-conflict transformation. In this case, the value of truth lies largely in the way it validates popular knowledge, which can be a psychologically and socially desirable end of research in a society emerging from conflict. Testimonial truth claims give important recognition to marginalised historical experiences in sites of conflict, where there are few other evidential traces than the words of a witness. Victims, relatives and others maintain a shadowy understanding of the meaning of truth and the purpose of telling it, with a strong sense that speaking "truth" matters to refute certain things that did not happen, or to assert things that definitely did happen. Therefore, research should place the "subject" of the research at the centre of the process: for instance, victim-centred truth-telling should focus on the bearer of testimony as

Braithwaite, J. 2013. 'Truth, reconciliation and peacebuilding'. In V. King, R. MacGill \& R.Wescombe (eds), Peace in action: practices, perspectives and policies that make a difference. Wagga Wagga: King MacGill Wescombe Publications, p. 30.

Lundy, P. \& McGovern, M. 2006. Participation, truth and partiality: participatory action research, community-based truth-telling and post-conflict transition in Northern Ireland. Sociology 40(1), pp. 84. 
the narrator of past experiences and active participant in truth-telling. Participation is a key principle in reaching the desired end-state of truth-telling.

Nabudere ${ }^{25}$ asserts that understanding people's views requires adopting an epistemology that recognises orality as a valid source of knowledge. Orality can only be interpreted with multiand interdisciplinary approaches to unravel the complexity of revelations, which is not possible within a single discipline. To see the world as systemic and more holistically, transdisciplinarity is also required. ${ }^{26} \mathrm{Nissani}^{27}$ explains that all research takes place along a continuum ranging from two imaginary poles, starting from disciplinary work to a grand synthesis of all human knowledge, achieved through disciplinary knowledge, with disciplinary, multidisciplinary, interdisciplinary and transdisciplinary research as "four arrows shot from a single bow of knowledge" towards a target. Velthuizen ${ }^{28}$ professes that transdisciplinary research is necessary to determine the causes of violent conflict. The researcher needs to break out of the stifling constraints of systems thinking and the linear processes of Western hermeneutics created by disciplinarity.

Therefore, the researcher should recognise that people in conflict might have varied experiences of reality. These realities need to be accessed, collated, integrated and synthesised for new knowledge to emerge, recognising the normative-spiritual realm that informs the epistemology and cosmology of Africa. It is in the village community that knowledge can be discovered and used to find lasting solutions to conflict, using various methods from all disciplines without being over-concerned about disciplinarity.

\section{Community-based participatory research (CBPR) as avenue for truth finding}

Community-based participatory research (CBPR) is an approach to research that equitably involves community members, organisational representatives and researchers in all aspects of the research process as partners who all contribute expertise, sharing decision-making and ownership. The aim of CBPR is to augment knowledge and understanding of a given experience, and to integrate that knowledge with interventions related to policies and social change, improving the quality of life of community members. ${ }^{29}$ Ideally the participatory approach to research is a democratic negotiated process between academic and community

25 Nabudere, D.W. 2006. Investment choices for education in Africa. Paper for DBSA/HSRC/Wits NEPAD Conference 19-21 September 2006, Johannesburg. Available at http://www.rrojasdatabank.info/devstate/Nabudere.doc (accessed 6 October 2014). Available at http://www.sciencedirect.com (accessed 14 October 2011).

Nissani, M. 1995. Fruit salads and smoothies: A working definition on interdisciplinarity. Journal of Educational Thought (29).

Velthuizen, A.G. 2012. The transdisciplinary approach to understanding the causes of wicked problems such as the violent conflict in Rwanda. The Journal for Transdisciplinary Research in Southern Africa, 8(1), pp. 51-62.

Israel, B.A., Schulz, A.J., Parker, E.A., Becker, A.B., Allen, A. \& Guzman, J.R. 2008. 'Critical issues in developing and following CBPR principles'. In M. Minkler \& N. Wallerstein (eds), Community-based participatory research for health: From process to outcomes (2nd ed.). San Francisco: Jossey-Bass, pp. 47-66. 
partners to ensure that the research process maintains social and cultural relevance, while at the same time scientific rigour is maintained. CBPR requires empowerment of people, ownership by the community and capacity-building while translating scientific knowledge into action. ${ }^{30}$ The CBPR approach is aligned with the modern view of anthropology - that research is not a study of people, but a study with people. The community is involved in the research planning, implementation and evaluation and dissemination of results to ensure diverse perspectives and capacity-building in the community. The research implies work and study with people, immersed with the people in an environment of joint activity, experience and educating perceptions of the world to "open our eyes and minds" to other possibilities of being. ${ }^{31}$

For research to be useful for policy change and to build healthy communities, practitioners of CBPR must take seriously notions of research rigour, validity and reliability. Practitioners of CBPR need to "broaden the bandwidth of validity" by ensuring that the research question is valid or relevant to the community and that different "ways of knowing," including community knowledge, are valued alongside scientific sources of knowledge. ${ }^{32}$

When these assertions concerning CBPR are evaluated and analysed, it is found that CBPR contains all the elements that are required for research where truth-seeking is a vital point of departure to finding solutions for challenges that emanate from violent conflict in the past, including the risk of sporadic violence re-emerging. CBPR is an ideal instrument for empirical investigation by seeking voluntary disclosure or deliberately uncovering facts by accessing the varied lived experiences of participants. In this regard, CBPR presents many opportunities to mitigate or overcome the barriers of language and personality in accessing data by allowing for a flexible application of research methods and approaches that works well in a specific environment. Furthermore, CBPR calls for a lengthy process to enable capturing and sifting of "noise" contained in narratives, and for an extensive process of evaluation, validation, moderation, storing, retrieval, analysis, synthesis, interpretation, learning and dissemination.

The above analysis reveals that the CBPR process is ideal for determining the accuracy of data by placing it into the context of the cosmology of a specific culture, considering the norms, spiritual influences and personal considerations of knowledge-holders. Access to many different worldviews and perspectives of what happened during conflict ensures triangulation of views and identification of recursive themes. Ensuring equity of perspectives makes it possible to break away from hegemonic power relationships that enforce specific paradigms and dominant narratives, so often the symptoms of persistent contest for power in a community. Moreover, CBPR creates the opportunity for researchers to collectively analyse

30 Cargo, M., Delormier, T., Lévesque, L., Horn-Miller, K., McComber, A. \& Macaulay, A.C. 2008. Can the democratic ideal of participatory research be achieved? An inside look at an academic-indigenous community partnership. Health Education Research, (235, pp. 904-914).

31 Ingold, T. 2011. Being alive: essays on movement, knowledge and description. New York: Routledge, p. 238.

32 Minkler, M., Garcia, A.P., Rubin,V. \& Wallerstein, N. 2008. Community-Based Participatory Research: a strategy for building healthy communities and promoting health through policy change. Available at http://www.policylink.org p.12 (accessed 1 October 2014). 
and interpret captured narratives through joint critical reflection to find a pattern of associations among variables and to judge what is probably true.

\section{Community-based participatory research with the San of Platfontein}

The San are the First People of Southern Africa, traced back to the last glacial maximum (about 20000 years ago) and still further back to "Mitochondrial Eve" 190000 years ago, the origin of all Africans. ${ }^{33}$ The modern history of the San is characterised by enslavement and the loss or limited use of ancestral land. During this time the San had to cope with conflict by withdrawing to remote areas. Some clans and individuals joined broader society to profit from interaction with traders, hunters and missionaries. ${ }^{34}$ Traditionally, the San developed an indigenous dispute resolution system suited to the needs of a collective hunter-gatherer society. ${ }^{35}$ Today San clans can be differentiated by the mutually unintelligible dialects they speak. For instance, Kwhedam is spoken by the San of the Okwa Valley of Botswana, the central Kalahari Desert, north-east Botswana, south-east Zambia and western Zimbabwe, while !Xun is spoken by the San living in the Tsumkwe area of Namibia, north-western Botswana, southern Angola and South Africa. ${ }^{36}$

The two groups of San living at Platfontein (Figure 1), the !Xun and the Khwe, are originally from northern Namibia and south-east Angola. . Traditionally, San clans never lived together in one village and preferred to stick to their own small groups or extended family units, away from other people. ${ }^{37}$ The Khwe were cultivators and cattle-herders who lived for centuries along the Kavango and Kwando Rivers in close contact with the Bantu groups of the Kavango region of Namibia and the Cuando-Cubango province of Angola The !Xun were mostly hunter-gatherers who lived in remote savannah areas. When the Portuguese ruled Angola, from 1966 the !Xun and the Khwe became trackers (called "flechas") serving the Portuguese military in southern Angola until 1975. ${ }^{38}$ In 1976, after Angola became independent from Portugal, the !Xun and Khwe were formed into a military unit (31 Battalion of the South African Defence Force) to participate in counter-insurgency operations in Angola. In March 1990, after Namibia became independent, the San were resettled at Schmidtsdrift on the Vaal River in the Northern Cape province of South Africa. ${ }^{39}$ In June 1996, the !Xun and Khwe became the owners of Platfontein, Wildebeeskuil and

Oppenheimer, S. 2004.Out of Africa's Eden. The peopling of the world. Johannesburg: Jonathan Ball.

Hohmann, T. (ed. 2003. 'Contesting land, development, identity and representation'. In The San and the State. Köln: Rüdiger Köppe Verlag.

Boulle, L. 2013. A history of alternative dispute resolution. ADR Bulletin 7(7), p.130. Available at http://epublications.bond.edu.au/adr/vol7/iss7/3 (accessed 17 July 2013).

Bleek, W. H. I. \& Lloyd, L. C. 1911. Specimens of Bushman folklore. London: George Allen \& Company.

Correspondence with Mario Mahongo, Traditional Leader of the !Xun, 27 November 2014.

Cann, J.P. 2013. The flechas. Insurgent hunting in eastern Angola, 1965-1974. 30 South Publishers: Africa@War series (11).

Robbins, D. 2007. The story of South Africa's discarded San soldiers. Johannesburg: Jonathan Ball. 
Droogfontein near Kimberley, the capital of the Northern Cape, and settled in Platfontein where they today live "in spatially segregated settlements". ${ }^{40}$

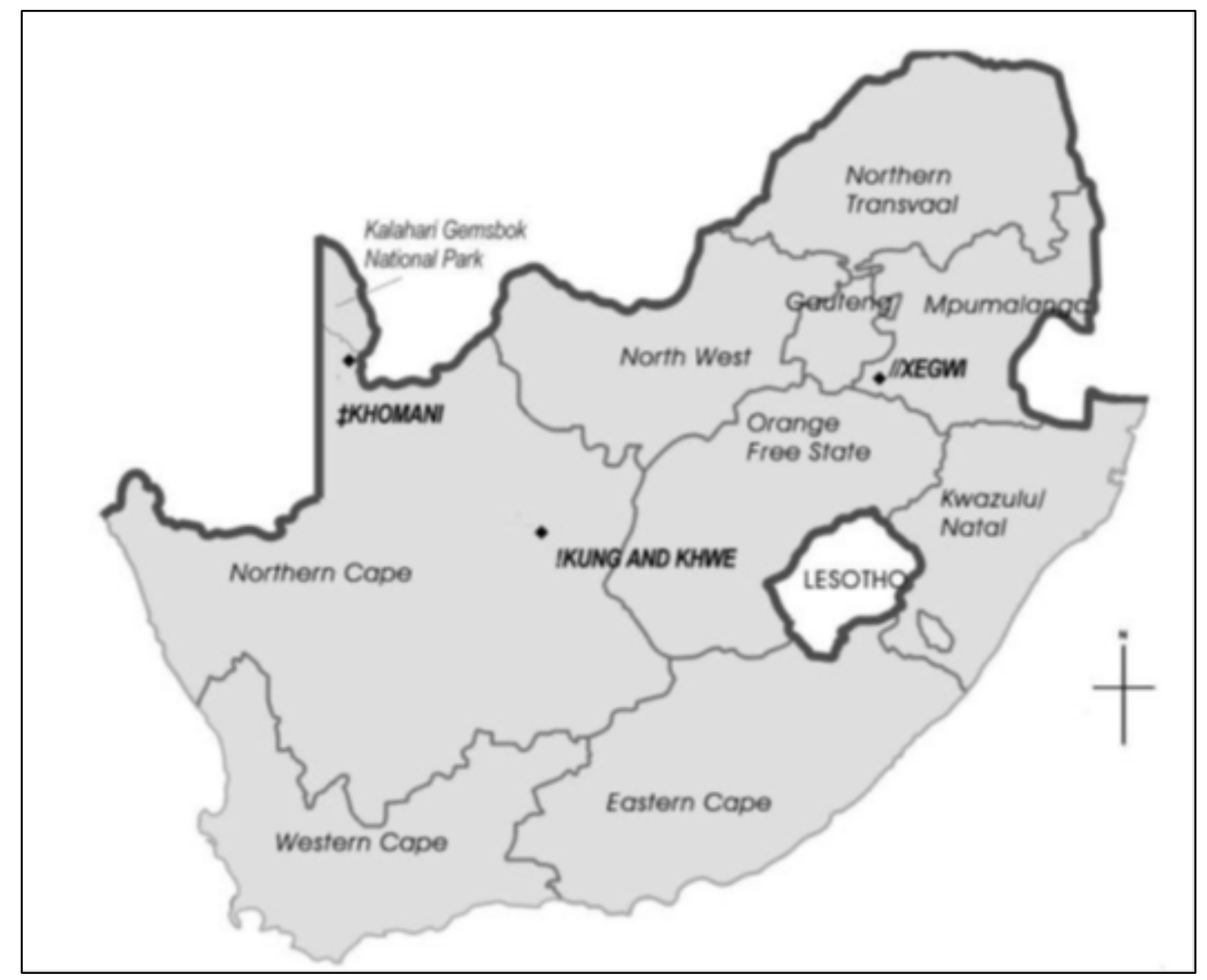

Figure 1: Location of the Platfontein San (!Xun and Khwe) in South Africa ${ }^{41}$

Internal disputes are persistent, with sporadic violence exacerbated by social ills such as alcoholism and drugs and frustrations over appalling living conditions. Furthermore, relationships between the community and governance authorities can at best be described as "uncertain", calling for dispute resolution capacity-building together with the community and research-driven interventions to break the cycle of poverty and violence that prevents the community taking its rightful place in South African society. ${ }^{42}$

Robins, S., Madzudzo, E. \& Brenzinger, M. 2006. 'Assessment of the status of the San in South Africa, Angola, Zambia and Zimbabwe'. In Regional Assessment of the Status of the San in Southern Africa Report Series (2). Windhoek: Legal Assistance Centre.

41 Robins, S., Madzudzo, E. \& Brenzinger, M. 2006. 'Assessment of the status of the San in South Africa, Angola, Zambia and Zimbabwe'. In Regional Assessment of the Status of the San in Southern Africa Report Series (2). Windhoek: Legal Assistance Centre.

42 Recurrent themes in the analysis of collated research reports found in the San Dispute Resolution Oral Archive. http://uir.unisa.ac.za (restricted access. 


\section{Data-gathering through voluntary disclosure during CBPR with the San of Platfontein}

Based on the assumption that truth-seeking is a vital element in finding solutions to dysfunctions that emanate from violent conflict, the Institute for Dispute Resolution in Africa (IDRA) launched a CBPR research project with the San of Platfontein under the auspices of the College of Law at Unisa. The community was selected for research because of their unique lived experiences and oral culture, enabling them to articulate what happened in their history, which was marked by violent conflict. Subsequently, research began in September 2013 with the informed consent of the San community. The research is conducted in three phases, namely a Discovery Phase that was concluded in September 2014, on ongoing Design Phase that will end in March 2015, to be followed by an Implementation Phase in 2015 when the designed solutions will be implemented. The discovery phase resulted in 250 research reports ${ }^{43}$ based on semi-structured interviews, focus group meetings and interpretation discussions. Approximately 1000 adults in Platfontein, including men and women of all ages, participated as knowledge-holders, adhering to the principle of equity in participation. Appreciative inquiry was used, meaning that questions focused on dispute resolution practices that had worked well in the past. Despite the positive intentions of appreciative inquiry, it was inevitable that knowledge was volunteered that reflected negative aspects that are associated with conflict. No voices were silenced and all who provided informed and voluntary consent, participated.

In Platfontein, there is always the risk of sporadic violence because of social ills such as drug abuse and alcoholism. However, determining how a history of violent conflict influences current violent behaviour is a complex process. ${ }^{44}$ Therefore, data-gathering had to access as many narratives as possible about the causes, dynamics and consequences of the conflict over a timeline of 60 years (starting with the origins of the community in Angola) and over a geographical area that covers the resettlements from Angola to Namibia to Schmidtsdrift to Platfontein. Furthermore, various actors and their past and present roles in conflict had to be analysed.

A general spirit of cooperation from most community members enabled thorough empirical investigation. Data was obtained mostly through voluntary disclosure to young fieldworkers who were trained by Unisa to gather data. Deliberate uncovering of facts was restricted to the Chief Investigator from Unisa, who engaged in informal discussions with specific individuals to clarify certain facts. However, it was found that a trade-off was needed between maintaining the trust of these individuals and the obligation to report. Eventually the Chief Investigator decided that no clarification discussions warranted a breach of trust.

The methods of data-gathering consisted of a triangulation of semi-structured interviews, focus group meetings and interpretative discussions. These methods ensured access to a variety of the lived experiences of participants, who in many cases confirmed the way in which different people experienced the same event, but also enabled the researchers to discover contradictions in the narratives.

43 The reports can be found on the San Dispute Resolution Oral Archive. http://uir.unisa.ac.za (restricted access).

44 Velthuizen, A. Interview with Angela Kedisaletse-Louw, Platfontein Social Worker, 10 September 2014. 
The research team found it exceptionally challenging to mitigate or overcome the barriers that language and personality placed on accessing data. All narratives had to be captured from !Xun and Khwe into Afrikaans or English (depending on what the fieldworker felt comfortable with) and then translated into English for processing. Sound recordings and selective video clips were made of all interviews and focus groups for verification purposes to mitigate the probable loss of important data, sift out unimportant noise and to allow for verification by the Chief Investigator, if necessary.

In the end, the research team was confident that the flexible application of research methods and approaches worked well in that specific environment, which is characterised by an embedded oral culture and limited writing skills, especially among older participants. Furthermore, the combination of methods allowed various kinds of personality to participate and tell their story in a community where excluding people is regarded with suspicion.

Before the research commenced it was acknowledged by researchers, sponsors and the community leadership that it would be a lengthy process. Therefore, sufficient time was planned to capture narrative data, write and transmit field research reports after sifting out the "noise" contained in narratives. However, the time required for the extensive process of evaluation, validation, moderation, storing, retrieval, analysis, synthesis, interpretation, learning and dissemination was underestimated, mainly because there were not enough sufficiently trained people to perform all these tasks while managing a project in the procrastinating bureaucracy that is associated with a big institution such as Unisa.

\section{Determining the accuracy of data during CBPR}

As discussed, determining the accuracy of data is an exceptional challenge when working with narratives in an oral culture. However, the many different worldviews and perspectives of what happened during conflicts enabled thematic analysis. First researchers and writers had to familiarise themselves with all the research reports in the San Dispute Resolution Oral archives (data corpus analysis). The next step was to conduct data item analysis (analysing all the reports looking for recursive keywords) and data extract analysis, (collating data into tables according to question/indicator numbers for coding). The data corpus analysis and data item analysis was applied by writers from several disciplines (who were invited to a writers' retreat in August 2014) to collated data in the San Dispute Resolution Oral archives. It was found that even experienced scholars did not have the skills to analyse collated data. A further attempt to do narrative analysis (analysis of selected narratives from specific data items and extracts) failed because the primary data contained in the narratives could only be accessed by a researcher who could understand and speak !Xun or Khwe, and such a person was not available. Using transcripts for analysis was not possible because these languages can only be written in the simplest form. These limitations were found to be a major constraint when academics trained in Western traditions try to analyse data from communities that do not speak English.

These limitations were overcome by allowing writers to apply their own knowledge of analysing data within their own disciplines. Key knowledge holders and field researchers from the San community participated in the writers' retreat together with the writers, assisting them with analysis, critical reflection and interpretation of the data. 
A strong point of the research was its success in maintaining equity of perspectives. The research avoided hegemonic control and manipulation, in the sense that no authority intervened in the research process. The research team was supported and allowed to follow the process that was agreed upon before the start of the research. At community level, great care was taken that power relationships in the community were not able to enforce specific paradigms. Dominant narratives were identified at a very early stage and avoided or moderated by deliberately allowing other voices to be heard, especially after persistent contests for power in a community were discovered.

\section{Judging the truth during CBPR}

CBPR creates the opportunity for researchers to collectively analyse and critically reflect on captured narratives. A series of conversations proved to be essential in verifying the accuracy of thematic analysis findings. A concentric circle approach was followed for interpretative conversations. In the centre of this circle were the elders of the community, who listened to presentations from the research team and corrected some inaccuracies. The next circle involved conversations between senior researchers from Unisa (including two post-doctoral fellows from Ethiopia) and the leaders of the community, in which valuable knowledge was exchanged to fill some gaps in the research. A further circle consisted of researchers, fieldworkers and practitioners who gathered in a major writers' retreat; during this session, the knowledge of the village community was effectively fused with that of other knowledgeholders. The writers' retreat, and analyses by the scholars in preparation for articles aimed at publication, revealed a pattern of associations among variables. It furthermore created the opportunity for the 12 scholars who participated to judge probabilities in the data presented.

The conversation circle was then expanded as a first effort at triangulating the findings of the research with other San communities. During a visit to the community of the $\neq$ Khomani San of Andriesvale (also in the Northern Cape province, $230 \mathrm{~km}$ north of the town of Upington, about $600 \mathrm{~km}$ from Platfontein), the results of the research were brainstormed with the leaders of Andriesvale and Platfontein, facilitated by Unisa researchers. Another visit to communities in Botswana is planned for early 2015 to complete the triangulation of the research findings.

A challenge that remains is for scholars from outside the community to determine the truth. The San of Platfontein live in the context of a cosmology that contains aspects of Western culture such as hierarchical thinking and disciplined behaviour, inherited from a history of militarisation and subservience. However, in general customary practices are maintained in the form of compassion, sharing, reciprocity, dignity of personhood, responsibility to others and interdependence, which underlie the humanistic principles of Africa. Scholars need to understand this context before judging the truth about knowledge claims. Together with spiritual influences such as the belief in witchcraft and the strong influence of 15 churches in Platfontein, the context of knowledge claims may be difficult to judge without insight into the cosmology and normative foundation of the San of Platfontein. These may overlap with those of other people but are probably different, taking into account the San's unique history of subservience, genocide, exploitation and militarisation as well as the current government neglect of the people of Platfontein. 


\section{Truth as premise for conciliation and development}

A rigorous research process ensured that the body of knowledge that was accumulated could be described as "probably true". Such a body of knowledge is a vital driver of the current Design Phase and the Implementation of Intervention Phase that is envisaged for 2015.

Ludema et $\mathrm{a}^{45}$ describe the design stage as systematic exploration by community members of what kinds of social architecture would translate their visions of best experiences from the past and hopes for the future into reality. During this phase the community, as a networked organisation, will merge with other organisations, donors, government officials and other communities as they interact. Participants in current disputes should admit their needs and contract to help one another grow, deliberately seeking and relying on mutual inputs and support.

To achieve successful design, further conversations with community knowledge-holders will take place, talking to different interest groups and mapping solutions to current conflicts. During the first week of November 2014, a large-scale conference was held with the community and invited scholars, during which participants developed a series of propositions to replace "what is" with "what might be". The conference provided a forum in which the researchers can share their findings and articulate their vision of and approach to build capacity for community dispute resolution.

The aim of the design phase is to generate energy for action and a sense of hope, excitement and cooperation as well as ownership of the future, leading to authentic positive change and innovation. The "socially constructive potential" of the community must be unlocked to replace existing "deficit constructions". A space should be created for new voices to emerge, expanding the circles of dialogue to build a "supportive relational context that allows for the positive construction of a new social reality" ${ }^{46}$ The Implementation Phase involves emphatic learning, focusing on the bilateral and inter-generational transfer of knowledge, recognising the different roles people play in a community. Learning will be in the form of a series of capacity-building workshops where joint experimentation will be guided by research results as a set of parallel, complementary processes of experimentation and dialogue. The workshops will be platforms for change, guided by the preservation of local culture to redistribute power by creating opportunities for self-empowerment through learning towards a new disputeresolution capacity. ${ }^{47}$

To achieve this vision, the aim is to launch joint initiatives. Two parallel activities are envisaged. The first set of interventions is a series of capacity-building seminars in the

Ludema, J.D., Cooperider, D.L. \& Barret, F.J. 2012. Appreciative inquiry: the power of the unconditional positive question. Available at http://www.2012waic.com/wpcontent/uploads/2012/05/Ludema-Cooperrider-Barrett-goed.pdf pp.7-9 (accessed 10 July 2013).

47 Hagos, A. 1996. 'Indigenous channels of communication, development and governance in Africa'. In M. Dia (ed), Africa's management in the 1990s and beyond: reconciling indigenous and transplanted institutions. Washington, D.C.: World Bank. 
community to transfer knowledge to community members in a structured way. A second set of interventions will involve other role players from outside the community who did not participate in the research but committed themselves to use the research results to deliver tangible change, transformation and innovation to intervene in the state of poverty in the community, the core cause of violent conflict.

\section{Conclusions}

This paper began with the aim of proposing some principles and practices for truth-seeking during research into violent conflict. To achieve this aim, an argument was deployed by analysing the concepts "truth", "myth" and "oral culture" as sources of knowledge. This conceptual analysis preceded a discussion of CBPR as a research methodology to access the knowledge of lived experiences embedded in the oral culture of the San community of Platfontein.

Concerning good practice, it was found that CBPR contains all the requirements for research in which empirical investigation, mitigation of language and personality barriers, flexible application of research methods and a thorough processing of knowledge claims to find probable truth are required. Furthermore, the integrative and intense intra-active character of the CBPR process is ideal for determining the accuracy of data in the context of a specific culture, considering the norms, spiritual influences and personal considerations of knowledge-holders that come with a unique cosmology. Moreover, many different worldviews and perspectives of what happened during the conflict ensuring equity of perspectives, as well as challenging hegemonic power relationships, paradigms, and narratives; ultimately informed judgement of what is probably true about a conflict.

CBPR with the San of Platfontein, involving an interconnected web of stakeholders and knowledge-holders, revealed the following principles that should inform CBPR involving communities with an oral culture and a history of violent conflict:

- Recognition of the community as a site of knowledge: Knowledge is the most important asset of a community that is in conflict or recovering from conflict. The community is the holder of this knowledge. The challenge facing researchers is to access this knowledge using methods that are acceptable to the community.

- Collaborative equitable partnerships: Equity in terms of gender, age and ethnicity is maintained through all phases of the research, including data discovery, information processing, dissemination of results, solution design and intervention.

- Emphatic learning and capacity-building: From the inception of the CBPR project all participants should learn from the activities until formal capacity-building embeds good practices.

- Holistic perspectives of conflict and disputes: A holistic perspective of the probable truth about causes, dynamics, actors and consequences is maintained in geographical/ecological, cultural and historic contexts.

- Integration of research with broader social innovation: CBPR is consequential, meaning that knowledge activates a series of interventions and events that lead to new ways of thinking and doing.

- Openly challenging divisionary thinking: Hegemonic, subservient relationships and manipulation of research are challenged through activities such as deliberately 
promoting equitable participation in truth-seeking, collaborative learning and joint solution design and implementation.

- Academic rigour complemented by social responsibility: The scientific quality of the research and research outputs is not negotiable. CBPR provides for rigorous maintenance of academic standards while opening the way for the social responsibility all scholars should actively pursue. 